\title{
Solution Structures of the C-Terminal Domain of Cardiac Troponin C Free and Bound to the N-Terminal Domain of Cardiac Troponin $I^{\dagger, \dot{*}}$
}

\author{
Geneviève M. C. Gasmi-Seabrook, ${ }^{\S}$ Jack W. Howarth, ${ }^{\S}$ Natosha Finley, ${ }^{\S}$ Ekram Abusamhadneh, ${ }^{\S}$ \\ Vadim Gaponenko, ${ }^{\S}$ Rui M. M. Brito," R. John Solaro, ${ }^{\perp}$ and Paul R. Rosevear*,, \\ Department of Molecular Genetics, Biochemistry, and Microbiology, University of Cincinnati, College of Medicine, 231 \\ Bethesda Avenue, Cincinnati, Ohio 45267, Department of Physiology and Biophysics, College of Medicine, University of \\ Illinois, Chicago, Illinois 60612, and Departamento de Quimica, Faculdade de Ciencias e Tecnologia, Universidade de \\ Coimbra, 3049 Coimbra, Portugal
}

Received February 4, 1999; Revised Manuscript Received April 19, 1999

\begin{abstract}
The N-terminal domain of cardiac troponin I (cTnI) comprising residues 33-80 and lacking the cardiac-specific amino terminus forms a stable binary complex with the C-terminal domain of cardiac troponin $\mathrm{C}(\mathrm{cTnC})$ comprising residues $81-161$. We have utilized heteronuclear multidimensional NMR to assign the backbone and side-chain resonances of $\mathrm{Ca}^{2+}$-saturated $\mathrm{cTnC}(81-161)$ both free and bound to $\operatorname{cTnI}(33-80)$. No significant differences were observed between secondary structural elements determined for free and $\mathrm{cTnI}(33-80)$-bound $\mathrm{cTnC}(81-161)$. We have determined solution structures of $\mathrm{Ca}^{2+}$-saturated $\mathrm{cTnC}(81-161)$ free and bound to $\mathrm{cTnI}(33-80)$. While the tertiary structure of $\mathrm{cTnC}(81-161)$ is qualitatively similar to that observed free in solution, the binding of $\operatorname{cTnI}(33-80)$ results mainly in an opening of the structure and movement of the loop region between helices $\mathrm{F}$ and $\mathrm{G}$. Together, these movements provide the binding site for the N-terminal domain of cTnI. The putative binding site for cTnI(33-80) was determined by mapping amide proton and nitrogen chemical shift changes, induced by the binding of $\mathrm{cTnI}(33-80)$, onto the C-terminal cTnC structure. The binding interface for $\mathrm{cTnI}(33-80)$, as suggested from chemical shift changes, involves predominantly hydrophobic interactions located in the expanded hydrophobic pocket. The largest chemical shift changes were observed in the loop region connecting helices $\mathrm{F}$ and $\mathrm{G}$. Inspection of available $\mathrm{TnC}$ sequences reveals that these residues are highly conserved, suggesting a common binding motif for the $\mathrm{Ca}^{2+} / \mathrm{Mg}^{2+}$-dependent interaction site in the TnC/ TnI complex.
\end{abstract}

The binding of $\mathrm{Ca}^{2+}$ to the troponin complex, located on the thin filament, triggers muscle contraction via $\mathrm{Ca}^{2+}$ induced conformational changes within the complex. Troponin consists of $\mathrm{TnC},{ }^{1}$ the $\mathrm{Ca}^{2+}$ binding subunit, which interacts with both TnI, the inhibitory subunit, and TnT, the tropomyosin binding subunit, on the actin-tropomyosin thin filament. Upon $\mathrm{Ca}^{2+}$ binding to the regulatory domain of $\mathrm{TnC}$, protein-protein interactions within the complex are

† This work supported by Grants AR 44324 and HL 41496 to P.R.R. and Grant HL 49934 to R.J.S. from the National Institutes of Health, and by NATO Science Fellowship 01B96PO to R.M.M.B.

Deposited in the Protein Data Bank under PDB file name 1GGS.

* To whom correspondence should be addressed at the Department of Molecular Genetics, Biochemistry, and Microbiology, University of Cincinnati, College of Medicine, 231 Bethesda Ave., Cincinnati, OH,45267.Phone: 513-558-3370.Fax: 513-558-847.Email: rosevear@ proto.med.uc.edu.

$\S$ University of Cincinnati.

"Universidade de Coimbra.

${ }^{\perp}$ University of Illinois.

${ }^{1}$ Abbreviations: Tn, troponin; cTnC, cardiac troponin C; sTnC, skeletal TnC; cTnI, cardiac troponin I; $\mathrm{cTnC}(81-161)$, recombinant C-terminal domain of cardiac $\mathrm{TnC}$ corresponding to residues $81-161$; cTnI(33-80), recombinant $\mathrm{N}$-terminal domain of cardiac TnI corresponding to residues 33-80; PMSF, phenylmethanesulfonyl fluoride; TFE, trifluoroethanol; DTT, dithiothreitol; rms, root-mean-square; IPTG, isopropylthiogalactoside; PKA, cyclic AMP-dependent protein kinase A. modified, facilitating the release of the inhibitory TnI domain from actin and triggering muscle contraction.

The cardiac isoforms of TnC and TnI both differ significantly from the skeletal forms. In the cardiac isoform of $\mathrm{TnC}$, site I is naturally inactive (1). Calcium binding to the $\mathrm{N}$-terminal regulatory domain of cTnC has been suggested to result in a "closed" conformation in contrast to $\mathrm{Ca}^{2+}$ activation of sTnC which results in a larger conformational change leading to an "open" form with an exposed hydrophobic pocket (2). The cardiac isoform of TnI is unique in that it contains an additional N-terminal extension of approximately 32 residues. This extension has two adjacent serine residues that can be phosphorylated by PKA. Phosphorylation has been demonstrated to modulate cardiac function by reducing the $\mathrm{Ca}^{2+}$ affinity for the $\mathrm{N}$-terminal regulatory site of cTnC (3). Cardiac TnC and TnI are known to interact in an antiparallel manner such that the C-terminal domain of $\mathrm{TnC}$ interacts with the N-terminal domain of TnI (4). An N-terminal fragment of cTnI, corresponding to residues $33-80$ and lacking the cardiac-specific $\mathrm{N}$-terminus, was found to be sufficient for interaction with the C-terminal domain of cTnC in a manner identical to that observed for cTnI(33-211), a full-length recombinant cTnI lacking the cardiac-specific amino terminus (4). Cardiac $\operatorname{TnI}(33-80)$ is homologous with the first 47 residues of sTnI. 
As a prerequisite to studying the intact cardiac TnIC complex, structural studies on the C-terminal domain of cTnC both free and bound to cTnI(33-80) were initiated. Shortly after we had completed the resonance assignment and elucidation of the secondary structure of $\mathrm{cTnC}(81-161)$ both free and bound to $\mathrm{cTnI}(33-80)$, a figure comparing the tertiary folds of the C-terminal domains of free skeletal and cardiac TnC became available (5). Structures of the free cardiac and skeletal C-terminal domains were found to be similar, as predicted. Although solution and crystal structures of isolated $\mathrm{TnC}$ domains are available, little structural information is available on the TnIC interaction. Recently, a cocrystal structure of skeletal TnC complexed with the $\mathrm{N}$-terminal 47 residues of skeletal TnI has been reported (6). A 31 residue $\alpha$-helical region of sTnI was shown to make both polar and van der Waals interactions with the C-terminal domain of sTnC. The overall conformation of the C-terminal domain of sTnC bound to $\operatorname{sTnI}(1-47)$ was found to be similar to that of the free protein (6). The major difference in the complex was an unwinding of the $\mathrm{D} / \mathrm{E}$ to an extended linker. This permitted the $\mathrm{N}$ - and $\mathrm{C}$-terminal domains of sTnC to come into close proximity, forming a narrow interdomain cleft in the sTnC/sTnI (1-47) complex (6).

We have determined the solution structure of $\mathrm{cTnC}(81-$ $161)$ both free and bound to cTnI(33-80). Structure comparison indicates that the free and bound structures are qualitatively similar, but do show some specific differences, mainly an opening of the structure and movement of the loop region between helices $\mathrm{F}$ and $\mathrm{G}$ in the bound form. Backbone amide resonances which undergo significant chemical shift changes upon complex formation have been identified and used to map the binding site for cTnI(33-80). Based on perturbation of residues undergoing large chemical shifts, the N-terminal domain of cTnI binds primarily to helix F, the short loop connecting helices $F$ and $G$, and the end of helix $\mathrm{H}$. These regions of cTnC constitute a major portion of the C-terminal hydrophobic pocket.

\section{MATERIALS AND METHODS}

Labeled Recombinant Proteins. Recombinant cTnC(81161) was cloned into pET23 $\mathrm{d}^{+}$and overexpressed in BL21(DE3) cells. Uniformly ${ }^{15} \mathrm{~N}$ - and ${ }^{13} \mathrm{C}$-enriched cTnC(81161) was obtained by growing BL21(DE3) cells with the appropriate plasmid in defined media (7). Routinely, $2 \mathrm{~L}$ of cells was grown at $37^{\circ} \mathrm{C}$ until an absorbance at $600 \mathrm{~nm}$ of 0.6 was reached. Cultures were induced with $1 \mathrm{mM}$ IPTG and grown overnight. Cells were collected by centrifugation, and lysed by treatment with lysozyme/sucrose followed by brief sonication. The cell suspension was centrifuged and the supernatant applied to a Pharmacia Q-Sepharose column equilibrated in buffer A (50 mM Tris, pH 7.5, and $6.2 \mathrm{mM}$ EDTA). Cardiac TnC(81-161) was eluted using a $0-1 \mathrm{M}$ $\mathrm{KCl}$ linear gradient. Fractions containing cTnC(81-161) were pooled, concentrated, and applied to a Pharmacia Superdex 75 column equilibrated in buffer A containing 150 $\mathrm{mM} \mathrm{NaCl}$. Fractions containing cTnC(81-161) were pooled, concentrated, and judged to be homogeneous by SDSpolyacrylamide gel electrophoresis and staining with Coomassie Brilliant Blue.

Recombinant cTnI(33-80) was cloned into $\mathrm{pET}^{+} \mathrm{d}^{+}$and overexpressed in BL21(DE3) in LB media. Cells were induced for $3 \mathrm{~h}$ with IPTG and harvested as described above. Since cTnI(33-80) is produced as inclusion bodies, cells were initially suspended in urea-containing buffer $(8 \mathrm{M}$ urea, $500 \mathrm{mM}$ Tris/HCl, pH 8.0, $500 \mathrm{mM} \mathrm{NaCl}, 1 \mathrm{mM}$ EDTA, $30 \mathrm{mM} \beta$-mercaptoethanol, and $1 \mathrm{mM}$ PMSF). The cell suspension was sonicated and centrifuged, and the pellet was discarded. The supernatant was dialyzed overnight against buffer B (6 M urea, 25 mM Tris/HCl, pH 8.0, 1 mM EDTA, $1 \mathrm{mM}$ PMSF, and $1 \mathrm{mM}$ DDT). The dialysate was centrifuged, and loaded onto a CM-Sepharose column equilibrated in buffer B. Cardiac cTnI(33-80) eluted at 25-40\% using a $0-750 \mathrm{mM}$ linear gradient. The sample was dialyzed against $300 \mathrm{mM} \mathrm{NaCl}, 10 \mathrm{mM}$ Tris, pH 8.0, 1 mM DTT, and $1 \mathrm{mM}$ PMSF. After dialysis, the sample was lyophilized, dissolved in buffer B, and loaded onto a Superdex 75 column equilibrated in buffer B containing $150 \mathrm{mM} \mathrm{NaCl}$. Cardiac cTnI(33-80) eluted as a symmetrical peak and was judged to be homogeneous by SDS-polyacrylamide electrophoresis and staining with Coomassie Brillant Blue.

Calcium-saturated $\left[{ }^{15} \mathrm{~N},{ }^{13} \mathrm{C}\right] \mathrm{cTnC}(81-161) / \mathrm{cTnI}(33-80)$ complex was formed by slowly adding cTnI(33-80) in buffer B into a solution of $\mathrm{cTnC}(81-161)$ and washing out the urea as previously described (4). In the absence of urea, any free $\mathrm{cTnI}(33-80)$ that does not bind to $\mathrm{cTnC}(81-161)$ precipitated from solution and was removed by centrifugation. The complex was also prepared by a slightly modified method of Jha et al. (8). No significant differences in the ${ }^{1} \mathrm{H}-{ }^{15} \mathrm{~N}$ HSQC spectra of $\mathrm{cTnC}(81-161)$ were observed for either method of complex formation.

Light Scattering Experiments. Dynamic light scattering experiments were conducted on $\mathrm{cTnC}(81-161)$ and $\mathrm{cTnC}$ $(81-161) / \mathrm{cTnI}(33-80)$, under the conditions of the NMR experiments as described below, using a Protein Solutions instrument. Sixteen independent measurements were performed for both samples. In both cases, results indicated $>95 \%$ monodisperse solutions with diffusion coefficients appropriate for the known molecular weights for free cTnC$(81-161)$ and the complex.

NMR Methods. NMR experiments were collected at 40 ${ }^{\circ} \mathrm{C}$ for both the free protein and the complex. Two separate $1 \mathrm{mM}$ samples of the free protein, $\left[{ }^{15} \mathrm{~N},{ }^{13} \mathrm{C}\right] \mathrm{cTnC}(81-161)$ or $\left[{ }^{15} \mathrm{~N}\right] \mathrm{cTnC}(81-161)$, were prepared in $\mathrm{NMR}$ buffer containing $20 \mathrm{mM}$ Tris- $d_{11}$, pH 6.8, $100 \mathrm{mM} \mathrm{KCl,} 20 \mathrm{mM}$ DTT, $15 \mathrm{mM} \mathrm{CaCl}, 0.1 \mathrm{mM}$ leupeptin, and $0.1 \mathrm{mM}$ pefabloc, $10 \% \mathrm{D}_{2} \mathrm{O}$. Two separate complex samples of $0.7-1 \mathrm{mM}\left[{ }^{15} \mathrm{~N},{ }^{13} \mathrm{C}\right] \mathrm{cTnC}(81-161) / \mathrm{cTnI}(33-80)$ or $\left[{ }^{15} \mathrm{~N}\right]-$ $\mathrm{cTnC}(81-161) / \mathrm{cTnI}(33-80)$ in the above NMR buffer were also prepared. ${ }^{1} \mathrm{H},{ }^{13} \mathrm{C}$, and ${ }^{15} \mathrm{~N}$ chemical shift referencing have been obtained following the guidelines proposed by Wishart et al. (9). The idea is to use indirect referencing for the multidimensional heteronuclear NMR experiment. The ${ }^{1} \mathrm{H}$ chemical shift standard was obtained from DSS in water $\left(1 \mathrm{mM}, \mathrm{pH} 7.0,40{ }^{\circ} \mathrm{C}\right.$ ). Both the ${ }^{13} \mathrm{C}$ and ${ }^{15} \mathrm{~N}$ chemical shifts were referenced to the frequency ratio: ${ }^{13} \mathrm{C} /{ }^{1} \mathrm{H}=0.25144953$ and ${ }^{15} \mathrm{~N} /{ }^{1} \mathrm{H}=0.101329118$, respectively. NMR experiments were performed on Varian 600 and $800 \mathrm{MHz}$ Inova spectrometers equipped with pulse-field gradient units and a pfg triple resonance probe. Sequential assignments were obtained from sensitivity-enhanced gradient $\operatorname{HSQC}(10),{ }^{15} \mathrm{~N}$ edited NOESY-HSQC with 70 and $150 \mathrm{~ms}$ mixing times and ${ }^{15} \mathrm{~N}$-edited TOCSY-HSQC (11), CN-NOESY-HSQC with a 150 ms mixing time (12), $\mathrm{HNC}_{\alpha} \mathrm{C}_{\beta}(13),\left(\mathrm{H}_{\beta}\right) \mathrm{C}_{\beta} \mathrm{C}_{\alpha}(\mathrm{CO}) \mathrm{NNH}$ 
(14), and HNCO (15) experiments. Spectra recorded for sidechain assignments include $\mathrm{H}(\mathrm{CCO}) \mathrm{NH}$ and $\mathrm{C}(\mathrm{CO}) \mathrm{NH}(16-$ 18) for the aliphatic resonances and $\left(\mathrm{H}_{\beta}\right) \mathrm{C}_{\beta}\left(\mathrm{C}_{\gamma} \mathrm{C}_{\delta}\right) \mathrm{H}_{\delta}$ and $\left(\mathrm{H}_{\beta}\right) \mathrm{C}_{\beta}\left(\mathrm{C}_{\gamma} \mathrm{C}_{\delta} \mathrm{C}_{\epsilon}\right) \mathrm{H}_{\epsilon}$ (19) for aromatic resonances. The threebond coupling constant ${ }^{3} J_{\mathrm{HN}-\mathrm{H} \alpha}$ was obtained from the HNHA experiment $(20,21)$. Coupling constants were calculated from the ratio of the intensity of the cross-peak $\left(I_{\mathrm{x}}\right)$ and the diagonal peak $\left(I_{\mathrm{d}}\right)$ according to

$$
I_{\mathrm{x}} / I_{\mathrm{d}}=\tan ^{2}\left[2 \pi\left({ }^{3} J_{\mathrm{HN}-\mathrm{H \alpha}}\right)\right]
$$

These coupling constants were related to the $\varphi$ dihedral angle using the relationship described by Vuister and Bax (20). A total of $13 \chi_{1}$ torsion angles were calculated using AngleSearch software (22) for $\mathrm{cTnC}(81-161)$ bound to cTnI(33-80). The ratios of cross-peak intensities for $\beta$-protons obtained from an $\operatorname{HNHB}(23,24)$ experiment as well as ${ }^{3} J_{\mathrm{HN}-\mathrm{H \alpha}}$ values and $\mathrm{HN}$ to $\mathrm{H}_{\beta}, \mathrm{HN}$ to $\mathrm{H}_{\alpha}, \mathrm{HN}_{i+1}$ to $\mathrm{H}_{\alpha}$, and $\mathrm{HN}$ to $\mathrm{HN}_{i+1}$ NOEs were used as input for conformational grid search in dihedral-angle space using $6^{\circ}$ steps to explore possible side-chain geometries in $\mathrm{cTnC}(81-161)$ bound to cTnI(33-80). Pulse sequences together with the experimental parameters used in resonance assignment of both free and bound $\mathrm{cTnC}(81-161)$ are listed in Table 1. Data were processed with either FELIX 97.2 (BioSym) or nmrPipe (25) and analyzed with the program FELIX 97.2.

Tertiary Structure Calculation. Three-dimensional structures based on interproton distance restraints were generated using the hybrid distance geometry-simulated annealing approach $(26-29)$ and the X-PLOR program (30). The topology and parameter files in X-PLOR were modified to incorporate specific characteristics for the $\mathrm{Ca}^{2+}$ ion. Values for distances between the calcium ion and the calcium binding ligands were taken from Strynadka and James (31). Interproton distances were derived from cross-peak intensities in the $70,150 \mathrm{~ms}{ }^{15} \mathrm{~N}$-edited NOESY-HSQC and $150 \mathrm{~ms}$ CN-NOESY-HSQC. Peak intensities from the NOE crosspeaks were classified as strong $(1.8-2.8 \AA)$, medium $(1.8-$ $3.7 \AA$ ), weak $(1.8-5.2 \AA)$, and very weak $(1.8-6.0 \AA)$ for $\mathrm{H}_{\mathrm{N}}$ to $\mathrm{H}_{\mathrm{N}}$ NOEs and were classified as strong $(1.8-3.6 \AA)$, medium $(1.8-4.6 \AA)$, weak $(1.8-5.8 \AA)$, and very weak $(1.8-7.0 \AA)$ for all others. Pseudoatom corrections were added to NOEs involving the methyl groups. To NOEs involving nonstereospecifically assigned methylene protons $(32,33)$, center averaging was employed. Two distance restraints were used for each hydrogen bond: one between the hydrogen and the acceptor atom of $1.8-2.0 \AA$ and the other between the donor heavy atom and the acceptor atom of 2.7-3.0 $\AA$. A set of 500 substructures was generated using the metric matrix distance geometry program (34) followed by the distance geometry-simulated annealing protocol as described in the X-PLOR manual (30). Torsion angle constraints were initialized to $5 \mathrm{kcal} \mathrm{mol}{ }^{-1} \mathrm{rad}^{-2}$; then at the beginning of the annealing they were increased to 200 $\mathrm{kcal} \mathrm{mol}{ }^{-1} \mathrm{rad}^{-2}$. The initial annealing temperature was 2000 $\mathrm{K}$, and $50 \mathrm{~K}$ decrements allowed the system to cool to a final temperature of $100 \mathrm{~K}$. Force constants for the NOEderived distance restraints were maintained at $50 \mathrm{kcal} /(\mathrm{mol}$ • $\AA^{2}$ ) through the whole refinement process, whereas the repulsive force constant was increased from $0.003 \mathrm{kcal} /(\mathrm{mol} \cdot$ $\left.\AA^{2}\right)$ to $4 \mathrm{kcal} /\left(\mathrm{mol} \cdot \AA^{2}\right)$. After refinement, 20 accepted
A
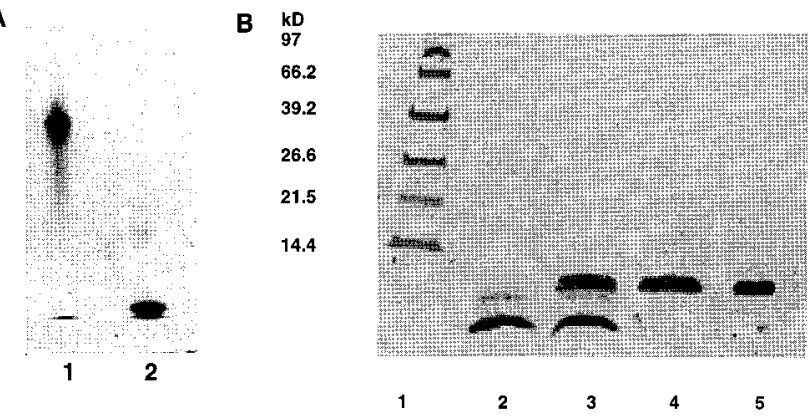

FIGURE 1: Complex formation between cTnC(81-161) and cTnI(33-80). (A) Native 15\% acrylamide gel electrophoresis of cTnC$(81-161)$ and $\mathrm{cTnI}(33-80)$ used to visualize the $\mathrm{cTnC}(81-161) \cdot$ cTnI(33-80) complex before NMR structural studies. Lane 1, cTnC(81-161)/cTnI(33-80) complex; lane 2, cTnC(81-161). (B) $15 \%$ SDS-polyacrylamide gel electrophoresis of cTnC(81-161), $\mathrm{cTnI}(33-80), \mathrm{cTnC}(81-161) \cdot \mathrm{TnI}(33-80)$ complex, and aprotinin. Lane 1, molecular mass standards (97 kDa, phosphorylase; 66.2 $\mathrm{kDa}$, bovine serum albumin; $26.6 \mathrm{kDa}$, triosephosphate isomerase; $21.5 \mathrm{kDa}$, trypsin inhibitor; $14.4 \mathrm{kDa}$, lysozyme); lane 2, cTnC$(81-161)$; lane 3, cTnC(81-161) • cTnI $(33-80)$ complex; lane 4, cTnI(33-80); lane 5, aprotinin (6.5 kDa).

structures for each, having no violations of the input NOE restraints greater than $0.2 \AA$, were analyzed. The ProcheckNMR program $(35,36)$ was used to check the structure quality.

Determination of Relaxation Parameters for $c \operatorname{TnC}(81-$ 161) Bound to $c \operatorname{TnI}(33-80) .{ }^{15} \mathrm{~N} T_{2}$ and $\left\{{ }^{1} \mathrm{H}\right\}-{ }^{15} \mathrm{~N}$ NOE spectra were acquired at $600 \mathrm{MHz}$. Pulse sequences used to record ${ }^{15} \mathrm{~N}$ NMR relaxation parameters are essentially those previously described (37). ${ }^{15} \mathrm{~N} \mathrm{~T}_{2}$ values were determined in a series of inversion-recovery experiments with delays (T) of 0, 32, 64, 96, 128, 160, 192, and 224 ms. Estimation of noise level was obtained with duplicate spectra at $T=0$, 64, and $160 \mathrm{~ms}$. Heteronuclear NOE values were obtained from eq 2 using peak intensities in the $\left\{{ }^{1} \mathrm{H}\right\}-{ }^{15} \mathrm{~N}$ NOE spectra:

$$
\mathrm{NOE}=I_{\mathrm{sat}} / I_{\text {unsat }}-1
$$

where $I_{\text {sat }}$ is the cross-peak intensity in the presence of proton saturation and $I_{\text {unsat }}$ is the cross-peak intensity in the absence of proton saturation. Spectra were recorded in the presence and absence of a proton presaturation period of $3 \mathrm{~s}$.

\section{RESULTS}

Complex Formation and Resonance Assignments. To study the interaction of recombinant $\mathrm{cTnC}(81-161)$ with recombinant $\operatorname{cTnI}(33-80)$, a 1:1 complex was formed between the two proteins by slowly adding aliquots of $\mathrm{cTnI}(33-80)$ in 6 $\mathrm{M}$ urea to a concentrated solution of $\mathrm{cTnC}(81-161)$. Urea was removed by repeated washing with NMR buffer. This procedure was repeated until a 1:1 complex was formed as previously described (4). Under conditions of complex formation, excess free cTnI(33-80) was insoluble and could be removed by centrifugation. Complex formation was monitored by SDS-polyacrylamide and native acrylamide gel electrophoresis (Figure 1). Native acrylamide gel electrophoresis demonstrated that $\mathrm{cTnC}(81-161) / \mathrm{cTnI}(33-80)$ formed a tight 1:1 complex (Figure 1A). SDS-polyacryla- 

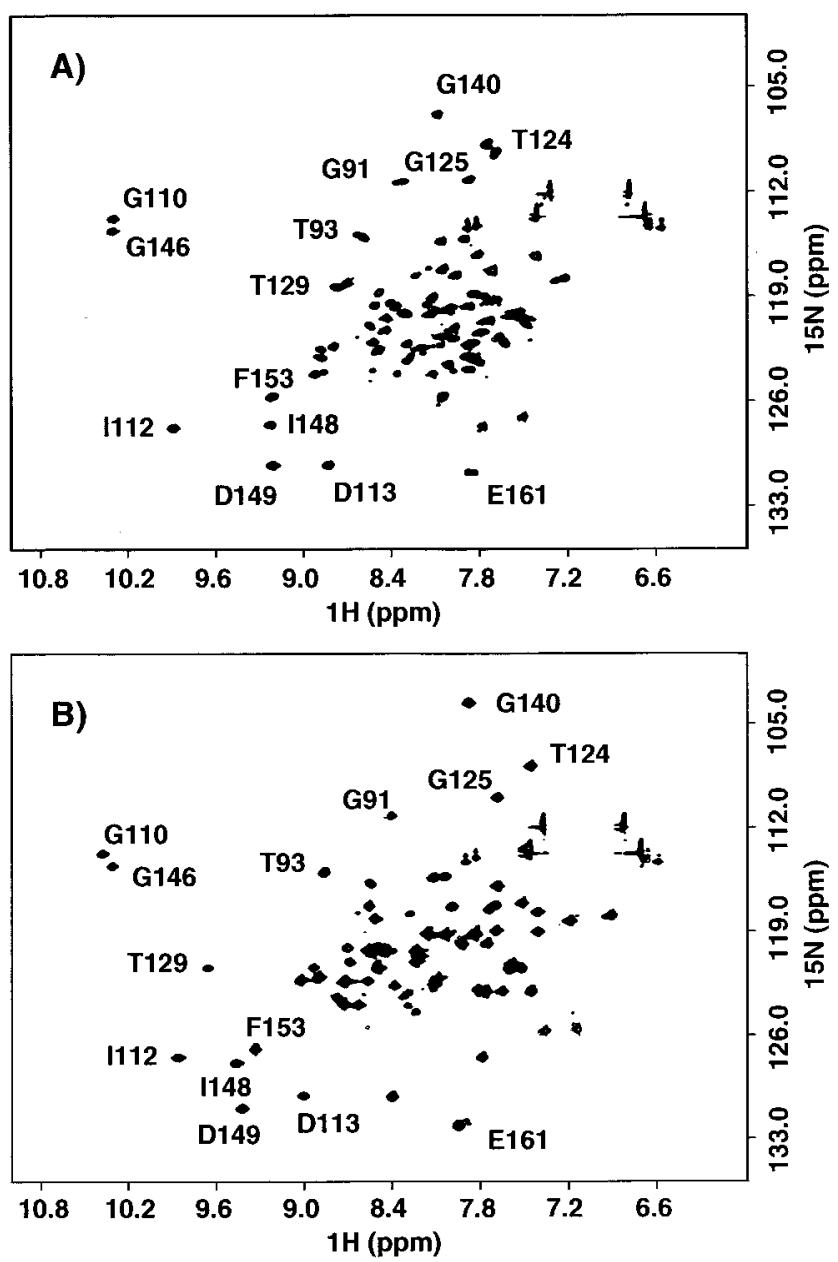

FIGURE 2: Two-dimensional ${ }^{1} \mathrm{H}-{ }^{15} \mathrm{~N}$ HSQC spectra of ${ }^{15} \mathrm{~N}$-labeled cTnC(81-161) free (A) and bound to cTnI(33-80) (B) recorded at $600 \mathrm{MHz}$. Several of the correlations are labeled corresponding to residue number.

mide gel electrophoresis was used to visualize the purity of the final complex (Figure 1B). The unusual mobility of $\mathrm{cTnC}(81-161)$ in the denaturing system is most likely due to residual $\mathrm{Ca}^{2+}$ binding at sites III and IV resulting in incomplete denaturation. Gel filtration using a Pharmacia Superdex 75 column yielded a single symmetrical peak at an elution volume consistent with the molecular mass of the complex $(15.2 \mathrm{kDa})$. In addition, dynamic light scattering intensities of $\mathrm{cTnC}(81-161)$, and $\mathrm{cTnC}(81-161) / \mathrm{cTnI}(33-$ 80 ), under conditions of the NMR experiment, indicated that $>95 \%$ of the free protein and the complex were monodisperse. The possibility of nonspecific hydrophobic interactions, particularly in free $\mathrm{cTnC}(81-161)$, was investigated by titration of a $1 \mathrm{mM}$ sample with TFE and monitoring the dynamic light scattering intensities. The addition of up to 15\% TFE did not decrease or alter the size of the particle distribution. Relaxation studies, presented below, also support the absence of aggregation of $\mathrm{cTnC}(81-161)$ under conditions of the NMR experiments.

Figure 2 compares the ${ }^{1} \mathrm{H}-{ }^{15} \mathrm{~N}$ HSQC spectra of ${ }^{15} \mathrm{~N}$ labeled $\mathrm{cTnC}(81-161)$ and the ${ }^{15} \mathrm{~N}$-labeled $\mathrm{cTnC}(81-161) /$ cTnI (33-80) complex. Comparison of the spectra indicates chemical exchange between the bound and free $\mathrm{cTnC}(81-$ $161)$ is slow on the NMR time scale. Titration of cTnI(33$80)$ into a solution of $\mathrm{cTnC}(81-161)$ was not feasible since cTnI $(33-80)$ is insoluble in the absence of urea or cTnC.
Of the 81 non-proline residues in $\mathrm{cTnC}(81-161), 78$ and $75{ }^{1} \mathrm{H}-{ }^{15} \mathrm{~N}$ correlations were observable in the free and bound forms, respectively. Assignments were made through analysis of experiments listed in Table 1. Backbone assignments were initiated from known residue assignments corresponding to Gly110, Gly146, Ile112, and Ile148 (4). In several cases, ${ }^{1} \mathrm{H}-{ }^{15} \mathrm{~N}$ correlations could be assigned to specific residue types based on selective ${ }^{15} \mathrm{~N}$-labeling experiments in full-length cTnC (4). In general, sequential backbone assignments were made using $\left(\mathrm{H}_{\beta}\right) \mathrm{C}_{\beta} \mathrm{C}_{\alpha}(\mathrm{CO}) \mathrm{NNH}$ and the $\mathrm{NHC}_{\alpha} \mathrm{C}_{\beta}$ spectra. Three-dimensional NOESY-HSQC spectra were used to confirm residue assignments by identifying sequential $d_{\mathrm{NN}}(i, i+1), d_{\mathrm{NN}}(i, i+3)$, and $d_{\alpha \mathrm{N}}(i, i+1)$ NOEs.

Identification of Secondary Structure. Secondary structures for $\mathrm{cTnC}(81-161)$ both free and in a complex with cTnI(33-80) were determined from analysis of NOE patterns, ${ }^{3} J_{\mathrm{HNH} \alpha}$ coupling constants, magnitude of the $d_{\mathrm{N \alpha} \alpha} / d_{\alpha \mathrm{N}} \mathrm{NOE}$ ratios (38), and the chemical shift index (CSI). The CSI was compiled utilizing $\mathrm{C}_{\alpha}, \mathrm{C}^{\prime}, \mathrm{C}_{\beta}$, and $\mathrm{H}_{\alpha}$ chemical shift values for $\mathrm{cTnC}(81-161)$ free and bound to $\operatorname{cTnI}(33-80)$ (3941). NOESY-HSQC spectra obtained with 70 and $150 \mathrm{~ms}$ mixing times and the CN-NOESY-HSQC spectrum recorded with a $150 \mathrm{~ms}$ mixing time were used to analyze NOE connectivities. A HNHA experiment was used to derive ${ }^{3} J_{\mathrm{HNH} \alpha}$ coupling constants. Values of ${ }^{3} J_{\mathrm{HNH} \alpha}$ greater than 8 $\mathrm{Hz}$ or smaller than $5 \mathrm{~Hz}$ were taken to indicate $\beta$-strand and $\alpha$-helix, respectively. Figure 3 presents a summary of the sequential and medium-range NOE, CSI, and ${ }^{3} J_{\mathrm{HNH} \alpha}$ coupling constant information used to determine the secondary structure of free and $\mathrm{cTnI}(33-80)$-bound $\mathrm{cTnC}(81-161)$. In free $\mathrm{cTnC}(81-161)$, four regions of helical structure were found corresponding to residues 93-103, 114-123, 130139 , and 150-158 (Figure 3A; Table 2). Two short $\beta$-strands were found between residues 111-113 and 147-149 (Figure $3 \mathrm{~A})$. The determined secondary structure is also consistent with that previously reported for the C-terminal domain of cTnC (5). In the free C-terminal domain, conformational exchange was observed for a number of residues in helices $\mathrm{F}$ and $\mathrm{H}$. Figure 3B summarizes the sequential and mediumrange NOEs, ${ }^{3} J_{\mathrm{HNH} \alpha}$ coupling constants, and CSI observed for $\mathrm{cTnC}(81-161)$ bound to $\mathrm{cTnI}(33-80)$. No secondary structural differences were observed in the bound protein (Figure 3, Table 2). Amide proton resonances for both Ile112 and -148 are shifted downfield, as observed in wild-type cTnC $(4,5)$, as a consequence of interstrand hydrogen bonding within the short $\beta$-sheet between calcium binding sites III and IV. The presence of these downfield-shifted amides can be used to monitor $\beta$-sheet formation upon $\mathrm{Ca}^{2+}$ binding to sites III and IV $(42,43)$. Cross-strand NOEs have also been found between $\mathrm{H}_{\alpha}-\mathrm{H}_{\alpha}$ and $\mathrm{H}_{\alpha}-\mathrm{NH}$ residues involved in the short $\beta$-sheet as was previously reported (42). Downfield chemical shifts are also observed for the amide protons of Gly110 and Gly146, as a consequence of hydrogen bonding with the carboxylate of Asp at position 1 in $\mathrm{Ca}^{2+}$ binding loops III and IV, respectively. The amide proton of Gly146 is shifted $0.05 \mathrm{ppm}$ more upfield in the complex than in free cTnC (Figure 2). This may reflect a weaker interaction between the amide of Gly146 and the side chain of Asp141 in the complex. The slight upfield shift of Gly146 in the complex can also be used to monitor complex formation and to ensure a 1:1 stoichiometry. In addition, the amide proton 


\begin{tabular}{|c|c|c|c|c|c|c|c|c|c|c|}
\hline \multirow[b]{2}{*}{ experiment } & \multicolumn{3}{|c|}{ nucleus } & \multicolumn{3}{|c|}{ data points } & \multicolumn{3}{|c|}{ spectral width $(\mathrm{Hz})$} & \multirow[b]{2}{*}{$\mathrm{nt}$} \\
\hline & $t 1$ & $t 2$ & $t 3$ & $t 1$ & $t 2$ & $t 3$ & $t 1$ & $t 2$ & $t 3$ & \\
\hline${ }^{15} \mathrm{~N}-{ }^{1} \mathrm{H}$ HSQC & ${ }^{15} \mathrm{~N}$ & ${ }^{1} \mathrm{H}$ & & 64 & 2048 & & 2000 & 8000 & & 8 \\
\hline${ }^{15} \mathrm{~N}$-edited & ${ }^{1} \mathrm{H}$ & ${ }^{15} \mathrm{~N}$ & ${ }^{1} \mathrm{H}$ & 64 & 32 & 1024 & 8000 & 2000 & 8000 & 28 \\
\hline \multicolumn{11}{|l|}{ NOESY-HSQC } \\
\hline${ }^{15} \mathrm{~N}$-edited & ${ }^{15} \mathrm{~N}$ & ${ }^{1} \mathrm{H}$ & ${ }^{1} \mathrm{H}$ & 32 & 128 & 1028 & 2000 & 8000 & 8000 & 16 \\
\hline \multicolumn{11}{|l|}{ TOCSY-HSQC } \\
\hline HNCO & ${ }^{13} \mathrm{CO}$ & ${ }^{15} \mathrm{~N}$ & ${ }^{1} \mathrm{H}$ & 64 & 32 & 1024 & 3500 & 1700 & 8000 & 32 \\
\hline $\mathrm{HNC}_{\alpha} \mathrm{C}_{\beta}$ & ${ }^{13} \mathrm{C}_{\alpha, \beta}$ & ${ }^{15} \mathrm{~N}$ & ${ }^{1} \mathrm{H}$ & 40 & 32 & 1024 & 9000 & 2000 & 8000 & 48 \\
\hline $\begin{array}{l}\left(\mathrm{H}_{\beta}\right) \mathrm{C}_{\beta} \mathrm{C}_{\alpha} \\
\text { (CO)NNH }\end{array}$ & ${ }^{13} \mathrm{C}_{\alpha, \beta}$ & ${ }^{15} \mathrm{~N}$ & ${ }^{1} \mathrm{H}$ & 46 & 32 & 1024 & 9000 & 2000 & 8000 & 40 \\
\hline $\mathrm{H}(\mathrm{CCO}) \mathrm{NH}$ & ${ }^{13} \mathrm{C}$ & ${ }^{15} \mathrm{~N}$ & ${ }^{1} \mathrm{H}$ & 64 & 32 & 1152 & 3600 & 2000 & 9000 & 16 \\
\hline $\mathrm{C}(\mathrm{CO}) \mathrm{NH}$ & ${ }^{13} \mathrm{C}$ & ${ }^{15} \mathrm{~N}$ & ${ }^{1} \mathrm{H}$ & 64 & 32 & 1152 & 9178 & 2000 & 9000 & 16 \\
\hline$\left(\mathrm{H}_{\beta}\right) \mathrm{C}_{\beta}\left(\mathrm{C}_{\gamma} \mathrm{C}_{\delta}\right) \mathrm{H}_{\delta}$ & ${ }^{13} \mathrm{C}$ & $1 \mathrm{H}$ & & 32 & 1152 & & 4800 & 9000 & & 64 \\
\hline$\left(\mathrm{H}_{\beta}\right) \mathrm{C}_{\beta}\left(\mathrm{C}_{\gamma} \mathrm{C}_{\delta} \mathrm{C}_{\epsilon}\right) \mathrm{H}_{\epsilon}$ & ${ }^{13} \mathrm{C}$ & $1 \mathrm{H}$ & & 32 & 1152 & & 4500 & 9000 & & 64 \\
\hline CN-NOESY- & ${ }^{1} \mathrm{H}$ & ${ }^{13} \mathrm{C}$ & ${ }^{1} \mathrm{H}$ & 100 & 32 & 960 & 6000 & 5000 & 9000 & 16 \\
\hline HSQC & & ${ }^{15} \mathrm{~N}$ & & & & & & & & \\
\hline $\mathrm{HNH}_{\alpha}$ & ${ }^{1} \mathrm{H}_{\alpha}$ & ${ }^{15} \mathrm{~N}$ & ${ }^{1} \mathrm{H}$ & 64 & 32 & 1024 & 6000 & 2000 & 8000 & 40 \\
\hline $\mathrm{HNH}_{\beta}$ & ${ }^{1} \mathrm{H}_{\beta}$ & ${ }^{15} \mathrm{~N}$ & ${ }^{1} \mathrm{H}$ & 64 & 32 & 1024 & 6600 & 2000 & 6600 & 64 \\
\hline
\end{tabular}

A)

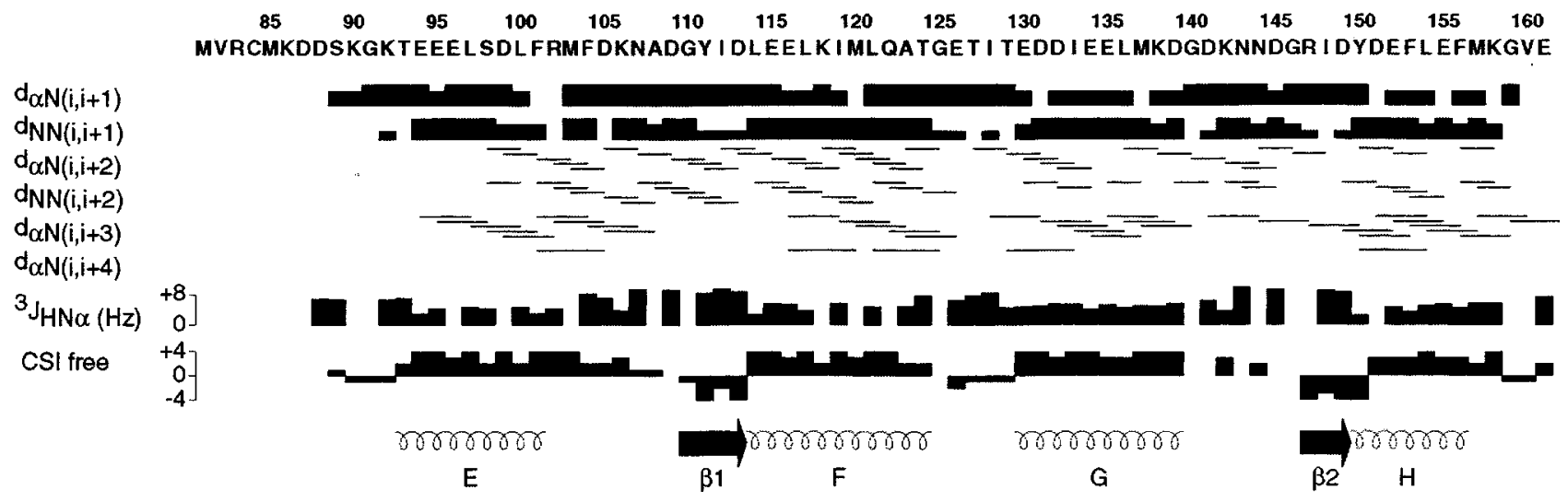

B)

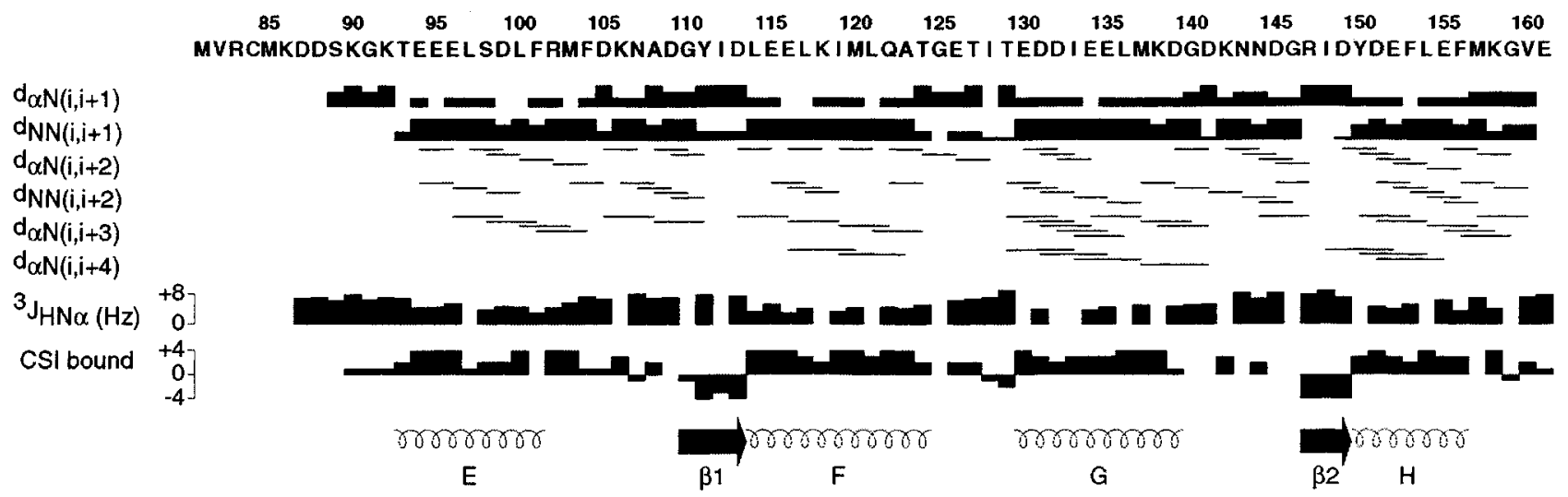

FIGURE 3: Summary of short- and medium-range NOE connectivites for NH and $\mathrm{C} \alpha \mathrm{H}$ protons, ${ }^{3} J_{\mathrm{HNH} \alpha}$ coupling constants, and consensus chemical shift index (CSI) for free (A) and cTnI(33-80)-bound (B) cTnC(81-161). Helices and $\beta$-strands determined form the data are shown aligned with the amino acid sequence.

of Thr129 is shifted downfield (Figure 2B) in cTnC(81161) upon binding $\mathrm{cTnI}(33-80)$. The downfield shift in the amide proton of Thr129 suggests formation of a tight hydrogen bond in the complex. This tight hydrogen bond is the result of Thr129 acting as an N-cap residue. As mentioned by Dasgupta and Bell (44), a specific pair of hydrogen bonds is often observed between the $\mathrm{N}$-cap side chain (often Thr) and the amide hydrogen of the residue at $\mathrm{N}+3$. The $\gamma$-hydroxyl group of Thr129 forms a hydrogen bond with the backbone amide of Asp132, and the side chain in turn forms a hydrogen bond with the amide of Thr129. Thr129 also exhibits the characteristic $\phi, \psi$ values for the $\mathrm{N}$-cap residue (45). In the bound structure, backbone torsional angles for $\phi\left(-87.3^{\circ}\right)$ and $\psi\left(+175.0^{\circ}\right)$ were found to be in the range expected for $\mathrm{N}$-cap residues. This is not observed in the free protein. The value of the ${ }^{3} J_{\mathrm{NH}-\mathrm{H} \alpha}$ coupling constant for Thr129 in the bound form was $9 \mathrm{~Hz}$ while in the free protein the ${ }^{3} J_{\mathrm{NH}-\mathrm{H \alpha}}$ coupling constant for Thr129 was found 
Table 2: Summary of Secondary Structural Elements for CTnC(81-161) Free and Complexed to CTnI(33-80)

\begin{tabular}{crc}
\hline \multirow{2}{*}{$\begin{array}{c}\text { secondary } \\
\text { structure }\end{array}$} & \multicolumn{2}{c}{$\mathrm{cTnC}(81-161)$} \\
\cline { 2 - 3 }$\alpha$-helix & & $\mathrm{cTnI}(33-80)$-bound \\
$\mathrm{E}$ & $93-103$ & \\
$\mathrm{~F}$ & $114-123$ & $93-103$ \\
$\mathrm{G}$ & $130-139$ & $114-123$ \\
$\mathrm{H}$ & $150-158$ & $130-139$ \\
$\beta$-sheet & $111-113$ & $150-158$ \\
& $147-149$ & $111-113$ \\
\hline
\end{tabular}

to be only $4.6 \mathrm{~Hz}$. Also, a $2 \mathrm{ppm}$ upfield shift in the ${ }^{13} \mathrm{C}_{\alpha}$ resonance and a $2.6 \mathrm{ppm}$ downfield shift in the ${ }^{13} \mathrm{C}_{\beta}$ resonance were observed for Thr129 of $\mathrm{cTnC}(81-161)$ when bound to $\operatorname{cTnI}(33-80)$. These chemical shift changes have been suggested to result from the unusually large value of $\psi$ for the N-cap residue (46). In the free protein, the amide hydrogen of Thr129 is too far away, $4.9 \AA$, from the side chain of Asp132 to form a hydrogen bond as compared to the complex where this distance is only $2.8 \AA$. In the skeletal complex, Thr127, homologous to Thr129 in cardiac, can form an intramolecular hydrogen bond with Glu130 (6).

Side-Chain Assignment of cTnC(81-161) Free and Bound to $\operatorname{Tn} I(33-80)$. Backbone assignments of the $\mathrm{H}_{\mathrm{N}},{ }^{15} \mathrm{~N},{ }^{13} \mathrm{C}_{\alpha}$, ${ }^{13} \mathrm{C}_{\beta}$, and $\mathrm{H}_{\alpha}$ resonances obtained from heteronuclear triple resonance three-dimensional experiments on $\left[{ }^{15} \mathrm{~N},{ }^{13} \mathrm{C}\right] \mathrm{cTnC}$ $(81-161)$ in both the free and bound forms were used as starting points for side-chain assignments. Side-chain signals were assigned from a series of 3D experiments including TOCSY-HSQC, H(CCO)NH, C(CO)NH, CN-NOESYHSQC, and NOESY-HSQC experiments (Table 1). Using this combination of experiments, extensive cross-checks could be made to avoid assignment errors. Resonances of most aliphatic and aromatic residues were unambiguously assigned in free $\mathrm{cTnC}(81-161)$. The aromatic rings of $\mathrm{Tyr}$ and Phe were assigned using a combination of $\left(\mathrm{H}_{\beta}\right) \mathrm{C}_{\beta}\left(\mathrm{C}_{\gamma} \mathrm{C}_{\delta}\right)$ -

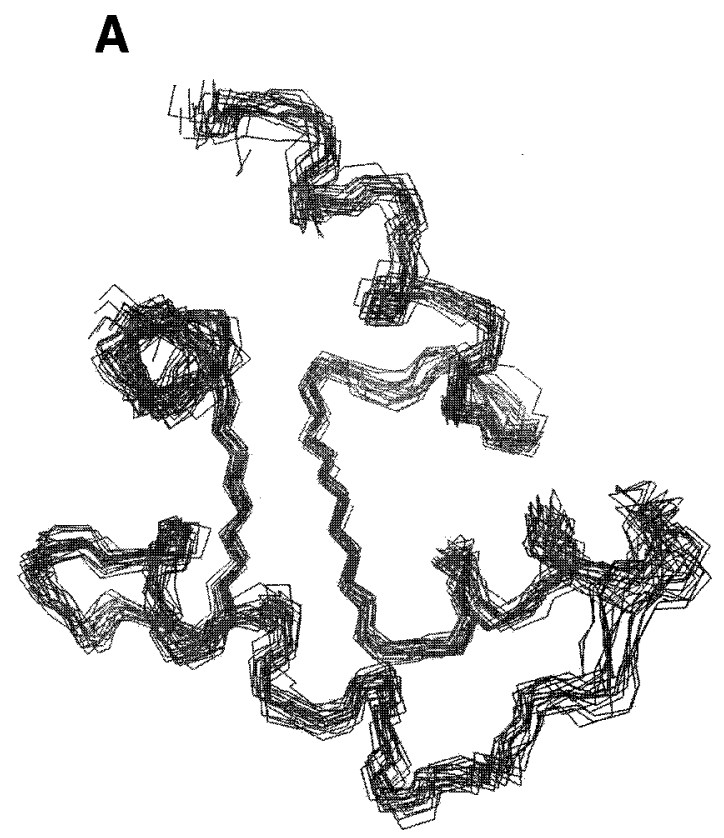

$\mathrm{H}_{\delta}$ and $\left(\mathrm{H}_{\beta}\right) \mathrm{C}_{\beta}\left(\mathrm{C}_{\gamma} \mathrm{C}_{\delta} \mathrm{C}_{\epsilon}\right) \mathrm{H}_{\epsilon}, \mathrm{CN}-\mathrm{NOESY-HSQC}$, as well as previous assignments on selectively Phe-labeled cTnC and DQF-COSY experiments of full-length cTnC (4). Aromatic spin systems previously delineated were sequentially assigned based on characteristic NOEs from the aromatic protons to the $\mathrm{NH}, \mathrm{C}_{\alpha} \mathrm{H}$, and $\mathrm{C}_{\beta} \mathrm{H}$ protons and NOEs with neighboring residues. Aliphatic side chains of Leu, Ile, and Val were assigned using a combination of CN-NOESY-HSQC, TOCSYHSQC, and NOESY-HSQC experiments. These experiments yielded significantly higher sensitivity in the free C-terminal domain of cTnC than in the higher molecular weight complex. Several side-chain $\mathrm{NH}_{2}$ resonances of Lys, Asn, and Gln were also assigned from the CN-NOESY-HSQC and NOESY-HSQC experiments. The inability to completely assign aliphatic side chains, particularly in the bound form, was the result of line broadening due to conformational exchange in the $\mathrm{C}$-terminal domain of cTnC, particularly for residues at the end of helix $\mathrm{F}$ and in the $\mathrm{H}$ helix. Spectral overlap precluded the sequence-specific assignment of several aliphatic side chains and characterization of their interresidue NOEs in both the free protein and the complex. Interestingly, in the $\mathrm{c} \operatorname{TnC}(81-161) / \mathrm{cTnI}(33-80)$ complex, the hydroxyl proton of Thr124 could be assigned as a broad resonance at $5.45 \mathrm{ppm}$ in the CN-NOESY-HSQC spectrum.

Free and cTnI(33-80)-Bound Structures of cTnC $(81-$ 161). Structures of the $\mathrm{Ca}^{2+}$-loaded forms of free and cTnI(33-80)-bound $\mathrm{cTnC}(81-161)$ were generated using the hybrid distance geometry-simulated annealing protocol. A final set of 20 accepted structures for the free and cTnI(33-80)-bound forms of $\mathrm{cTnC}(81-161)$ are given in Figure 4. The region 81 through 93 is highly disordered as evidenced by a lack of NOEs, by the amide proton exchange rates, and also by the magnitude of ${ }^{15} \mathrm{~N}\left\{{ }^{1} \mathrm{H}\right\}$ heteronuclear NOEs for cTnC(81-161) in the bound complex (Figure 5). Both the free and $\mathrm{cTnI}(33-80)$-bound forms of $\mathrm{cTnC}(81-161)$ exhibit well-defined EF-hand folded domains. Structural statistics for both free and $\mathrm{cTnI}(33-80)$-bound $\mathrm{cTnC}(81-161)$ are

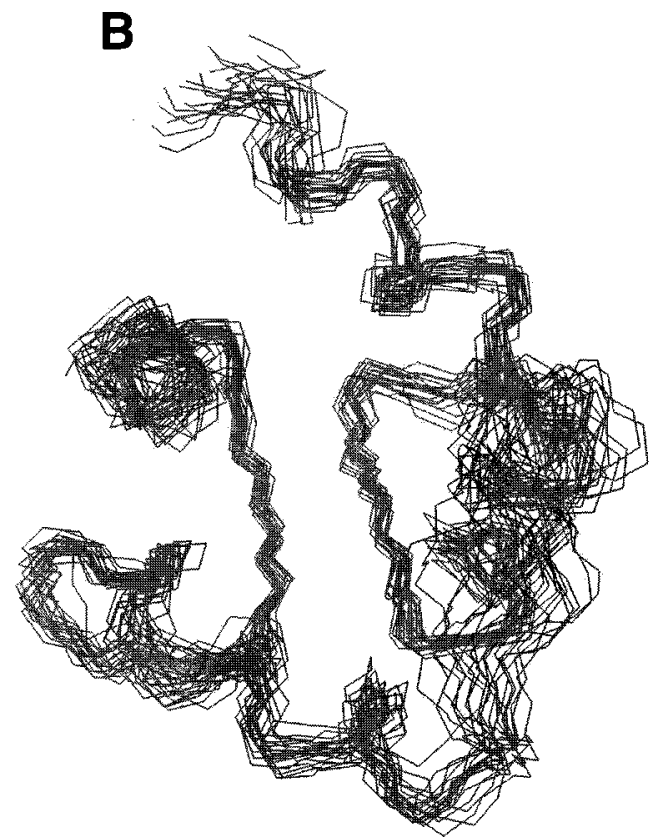

FIGURE 4: Final set of 20 accepted structures for $\mathrm{cTnI}(33-80)$-bound (A) and free (B) forms of cTnC(81-161). Residues 81 through 94 are disordered in both the free and bound forms of $\mathrm{cTnC}(81-161)$. The backbone atoms $\left(\mathrm{N}, \mathrm{C} \alpha, \mathrm{C}^{\prime}\right)$ of residues 93 through 161 are shown in both the free and bound forms. 

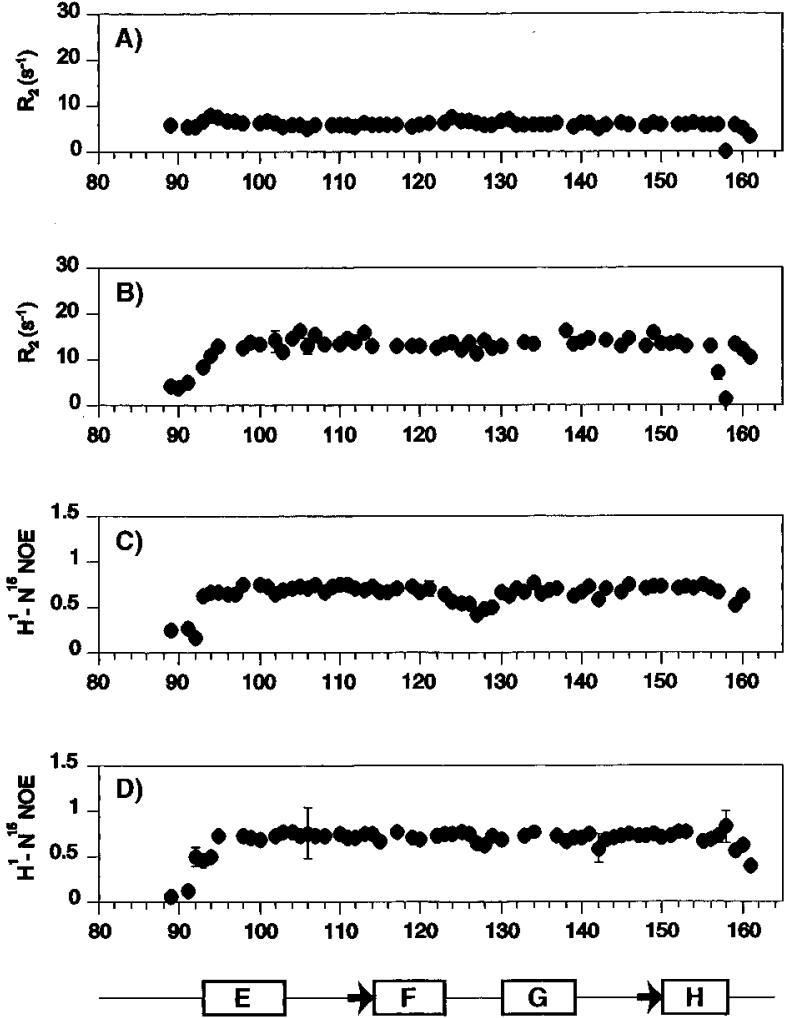

FIGURE 5: Relaxation parameters for free and cTnI(33-80)-bound cTnC $(81-161) .{ }^{15} \mathrm{~N}$ transverse relaxation rates for free (A) and cTnI $(33-80)$-bound $\mathrm{cTnC}(81-161)$ (B). $\left\{{ }^{1} \mathrm{H}\right\}-{ }^{15} \mathrm{~N}$ steady-state NOE values for free $(C)$ and $\mathrm{cTnI}(33-80)$-bound $\mathrm{cTnC}(81-161)$ (D). Data were acquired at $600 \mathrm{MHz}$ as described under Materials and Methods. The overall secondary structure of $\mathrm{cTnC}(81-161)$ bound to $\mathrm{cTnI}(33-80)$ is provided at the bottom.

given in Table 3. The global folds for both the free and bound forms of $\mathrm{cTnC}(81-161)$ are defined by 119 and 120 , respectively, long-range NOEs. The superposition of backbone atoms $\left(\mathrm{N}, \mathrm{C} \alpha, \mathrm{C}^{\prime}\right)$ for the 20 best free and bound structures of $\mathrm{cTnC}(81-161)$ yields rms deviations of 1.0 and $0.72 \AA$, respectively (Table 3 ). Ramachandran plots, calculated with the program Procheck-NMR V.3.4.4, for the free and bound forms of $\mathrm{cTnC}(81-161)$ showed that 78 and $87 \%$, respectively, of the amino acid residues fall in the most favorable $\psi, \phi$ regions including all residues in loop regions. Our structure for the free C-terminal domain of cTnC is very similar to that previously reported by Sykes' group (5). Conformational differences were observed between the more biologically relevant cTnI-bound form of cTnC $(81-161)$ and the free protein (Figure 6). The rms deviation between $\mathrm{C} \alpha$ atoms for the average free and bound $\mathrm{cTnC}(81-161)$ structures was $1.8 \AA$. Conformational differences within the free and bound structures can be observed by comparison of interhelical angles (Table 4). The binding of cTnI(3380) results mainly in an opening of the structure. In the free protein, NOEs are observed from the aromatic group of Phe104 to the methyl of Ala123. However, in bound cTnC$(81-161)$, these NOEs are absent since the ends of helices $\mathrm{E}$ and $\mathrm{F}$ have moved away from each other (Figure 6). The side chain of Phe104 is rotated in bound cTnC $(81-161)$, explaining the absence of NOEs with Ala123 that were observed in the free protein. Interactions between the aromatic ring of Phe104 and residues located at the beginning of the F helix are essential for holding the F helix in close

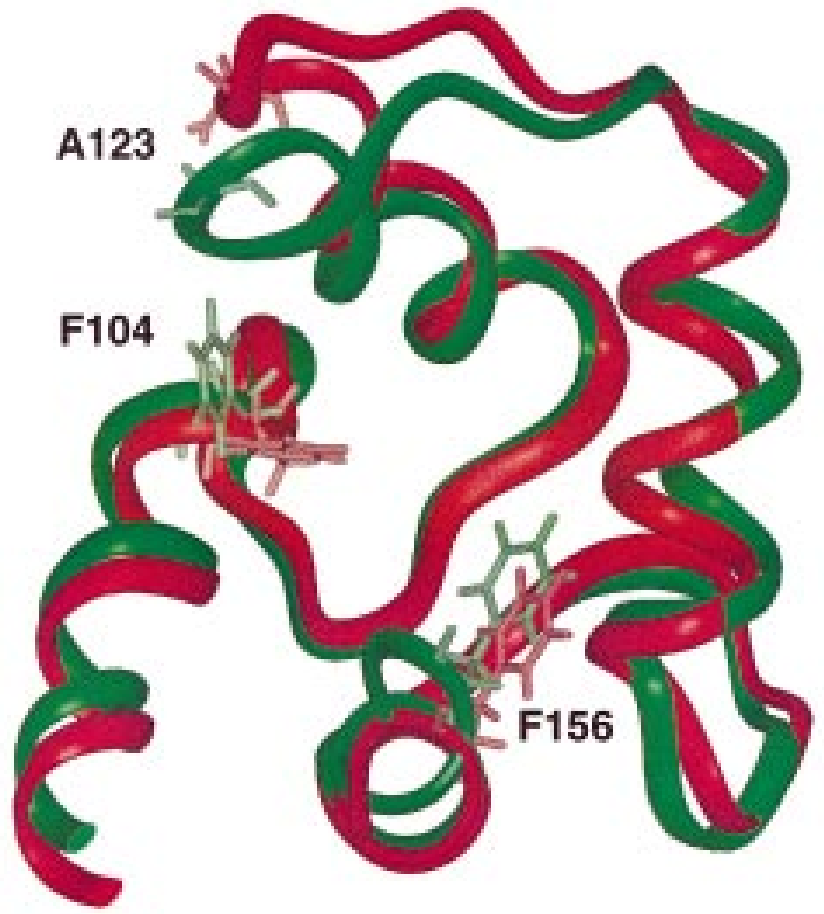

FIGURE 6: Ribbon diagram showing the best fit superposition of mean structures for free and $\mathrm{cTnI}(33-80)$-bound cTnC(81-161). The C-terminal domain of cTnC contains four $\alpha$-helices (E, F, G, and $\mathrm{H}$ ) and a short antiparallel $\beta$-sheet located between calcium binding sites III and IV. Free cTnC $(81-161)$ is represented in green, and $\mathrm{cTnI}(33-80)$-bound $\mathrm{cTnC}(81-161)$ is represented in red. Side chains of Phe104, Ala123, and Phe156 are shown to illustrate differences between the free and bound forms.

Table 3: Statistics for $\mathrm{Ca}^{2+}$-Saturated $\mathrm{CTnC}(81-161)$ Free and CTnI(33-80)-Bound Structures

\begin{tabular}{lll}
\hline & \multicolumn{2}{c}{ number } \\
\cline { 2 - 3 } & free & bound \\
\hline distance restraints & 678 & 788 \\
total NOE & 168 & 227 \\
intraresidue NOE & 242 & 271 \\
sequential NOE & 149 & 170 \\
medium-range NOE & 119 & 120 \\
long-range NOE & 4 & 4 \\
hydrogen bond distance & 60 & 92 \\
dihedral & 742 & 884 \\
total restraints & $\langle\mathrm{SA}\rangle^{a}$ & $\langle\mathrm{SA}\rangle$ \\
X-PLOR energies $(\mathrm{kcal} / \mathrm{mol})$ & 81 & 85 \\
$E_{\text {total }}$ & 1.1 & 1.3 \\
$E_{\text {bond }}$ & 67 & 69 \\
$E_{\text {angle }}$ & 11 & 11 \\
$E_{\text {improper }}$ & 1.3 & 2.6 \\
$E_{\mathrm{vdw}}$ & 0.9 & 1.1 \\
$E_{\text {NOE }}$ & 0.05 & 0.2 \\
$E_{\text {cdih }}$ & $\langle\mathrm{SA}\rangle$ & $\langle\mathrm{SA}\rangle$ \\
rmsd values & 1.0 & 0.72 \\
backbone & \\
helices, $\beta$-sheets, and Ca ${ }^{2+}$ loops $^{c}$ & 0.8 & 0.60 \\
violations & & \\
distance restraints & 0 & 0 \\
dihedral restraints & 0 & 0 \\
\hline
\end{tabular}

${ }^{a}\langle\mathrm{SA}\rangle$ is the ensemble of 20 final X-PLOR structures. Interresidue restraints can be defined as NOEs between side-chain protons that are more than four bonds apart. ${ }^{b}$ Residues $94-158 .{ }^{c}$ Residues $94-124$ and $130-158$.

proximity to helix E. Movement of helix $\mathrm{H}$ results in a translation of the aromatic ring of Phe156 away from residues 
Table 4: Interhelical Angles in $\mathrm{Ca}^{2+}$-Saturated CTnC(81-161) Free and $\mathrm{CTnI}(33-80)$-Bound

\begin{tabular}{cccc}
\hline & \multicolumn{3}{c}{$\mathrm{cTnC}(81-161)$ interhelical angles $(\mathrm{deg})^{a}$} \\
\cline { 2 - 4 } helix pair & free & $\mathrm{cTnI}(33-80)$-bound & $\mathrm{sTnC} / \mathrm{sTnI}(1-47) \mathrm{X}$-ray \\
\hline E/F & $112 \pm 7$ & $94 \pm 8$ & 99 \\
$\mathrm{G} / \mathrm{H}$ & $116 \pm 7$ & $89 \pm 8$ & 109 \\
\hline
\end{tabular}

${ }^{a}$ Calculated using a program from Mitsuhiko Ikura from the University of Toronto. Calculated using the 20 NMR-derived solution structures for both the free and $\mathrm{cTnI}(33-80)$-bound forms of $\mathrm{cTnC}(81-$ 161). The start and end points for the helices are as follows: E, 93103; F, 114-123; G, 130-139; H, 150-158. ${ }^{b}$ Calculated from the sTnC/sTnI(1-47) crystal structure by Vassylyev et al. (6).

at the beginning of helix F (Figure 6). These movements promote a small "opening" in the structure as observed by the slight decrease in the $\mathrm{E} / \mathrm{F}$ and $\mathrm{G} / \mathrm{H}$ interhelical angles (Table 4). The consequence of this is that the C-terminal domain is less compact than in the free structure. This opening is also responsible for movement of the loop, residues 124 through 129, connecting helices $F$ and $G$ (Figure 6 ). The hydroxyl proton of Thr124 could be assigned as a broad resonance at $5.45 \mathrm{ppm}$ in the CN-NOESY-HSQC spectrum in the complex. Nuclear Overhauser effects were observed from the hydroxyl proton of Thr124 to its own amide and to the amide proton of Glu126 only in the bound protein. Formation of a hydrogen bond between the $\mathrm{H} \gamma_{1}$ of Thr124 and the backbone carbonyl of Leu121 could help stabilize the loop region in the bound structure. Together, the results of these movements provide the binding site for the N-terminal domain of cTnI.

The binding site for cTnI(33-80) was determined by mapping amide proton and nitrogen chemical shift changes onto the C-terminal cTnC structure. Figure 7A shows a molecular surface for the bound form of $\mathrm{Ca}^{2+}$-saturated cTnC $(81-161)$ with residues whose amide proton or nitrogen chemical shifts are significantly perturbed upon complex formation. For comparison, a similar view is shown for the free protein (Figure 7B). Chemical shift differences were measured from the ${ }^{1} \mathrm{H}-{ }^{15} \mathrm{~N}$ HSQC spectra of ${ }^{15} \mathrm{~N}$-labeled cTnC $(81-161)$ both free and bound to $\mathrm{cTnI}(33-80)$ (Figure $2)$. Resonances for both free and bound $\mathrm{cTnC}(81-161)$ were independently assigned since a titration with free cTnI(3380) could not be readily performed due to its insolubility. The largest chemical shift changes were observed in the loop region connecting helices $\mathrm{F}$ and $\mathrm{G}$ as well as the beginning of helix $\mathrm{G}$ and the end of helix $\mathrm{H}$. The largest rms deviations for individual amino acid residues between the free and bound structures were also found for residues in the loop region between helices $F$ and $G$ and residues in the C-terminal portion of helix H. Many of the amino acid residues in $\mathrm{cTnC}$, whose chemical shifts were perturbed upon cTnI(33-80) binding, are conserved in sTnC and found to interact with sTnI in the $\mathrm{X}$ - ray structure (6). The backbone rms deviation between residues $94-158$ in cTnC bound to cTnI(33-80) and residues 92-156 of sTnC in the crystal structure was $1.5 \AA$. This general agreement between the solution structure for $\mathrm{cTnC}(81-161) / \mathrm{TnI}(33-80)$ and the crystal structure for $\mathrm{sTnC/cTnI}(1-47)$ suggests a common binding motif for the $\mathrm{Ca}^{2+} / \mathrm{Mg}^{2+}$-dependent interaction site in the TnIC complex.

\section{DISCUSSION}

We have compared structures of the C-terminal domain of cTnC both free in solution and bound to the $\mathrm{N}$-terminal domain of cTnI. The structure of free cTnC(81-161) is nearly identical to that previously determined for the $\mathrm{C}$ terminal domain of cTnC (5), as well as for the crystal structure of the C-terminal domain of sTnC (47). However, in the complex, an opening of the hydrophobic pocket occurs as a consequence of movement in helices $\mathrm{E}, \mathrm{F}$, and $\mathrm{H}$ to accommodate binding of the N-terminal domain of cTnI. Movement of the loop, residues 124-129, connecting helices $\mathrm{F}$ and $\mathrm{G}$ is also important for formation of the cTnI binding pocket (Figure 6). The consequence of these movements is that the C-terminal domain is less compact than in the free structure providing the binding site for the $\mathrm{N}$-terminal domain of cTnI. This conformational change results in a rms deviation for backbone atoms between free and cTnI(3380)-bound cTnC(81-161) of $1.9 \AA$ (residues 94-158).

Binding of sTnI $(1-47)$ to sTnC was also found to not greatly perturb the conformation of the $\mathrm{C}$-terminal domain of sTnC (6). In skeletal TnC, the rms deviation for $\mathrm{C} \alpha$ atoms between the free and $\operatorname{cTnI}(1-47)$-bound $\mathrm{C}$-terminal domains of sTnC was only $1.1 \AA$ (6). Comparison of the $\mathrm{C} \alpha$ atoms for bound skeletal and cardiac structures gives a rms deviation of $1.5 \AA$. Essential agreement between the cardiac and skeletal structures is further supported by the residues showing the largest rms deviations between the free and bound structures. The $\mathrm{C} \alpha$ residues showing the largest deviation between the average free and bound forms for cTnC(81-161) are Glu95 and -135, and the region comprising residues 122 through 128 (Figure 6). This region includes the end of helix F, the loop region between helices $F$ and $G$, and the end of helix $\mathrm{H}$. The largest $\mathrm{C} \alpha$ residue rms deviations between the C-terminal free and bound forms of sTnC also occur in the loop region between helices $F$ and $G(6)$.

$\left\{{ }^{1} \mathrm{H}\right\}-{ }^{15} \mathrm{~N}$ heteronuclear NOEs for $\mathrm{cTnC}(81-161)$ show a decrease in mobility for the loop region between helices $\mathrm{F}$ and $\mathrm{G}$ upon binding cTnI(33-80) (Figure 5C,D). This result is consistent with the observed decrease in available conformational space for backbone atoms in this region upon binding cTnI(33-80) (Figure 4). The magnitude of ${ }^{15} \mathrm{~N}$ transverse relaxation rates for $\mathrm{cTnC}(81-161)$ is consistent with the free and cTnI(33-80)-bound proteins having different overall tumbling times (Figure 5A,B). However, a decrease in ${ }^{15} \mathrm{~N}$ transverse relaxation rates was not observed in the loop region between helices $\mathrm{F}$ and $\mathrm{G}$ in free cTnC$(81-161)$. This is likely due to the fact that individual local motions in this region are not significantly faster than the overall tumbling of the molecule. However, this decrease in ${ }^{15} \mathrm{~N}$ transverse relaxation rates for the loop region between helices $\mathrm{F}$ and $\mathrm{G}$ in free full-length $\left[{ }^{15} \mathrm{~N},{ }^{2} \mathrm{H}\right] \mathrm{cTnC}$ has been observed (48). Additional relaxation studies of side chains are needed to develop a more comprehensive picture of the mobility occurring at the interface between these two proteins. Restriction of backbone mobility upon complex formation is not unusual (49-51). Thus, some of the apparent differences observed in the loop region between free and bound $\mathrm{cTnC}(81-161)$ may result from differences in the flexibility in the loop regions. Studies of side-chain dynamics for cTnC bound to N-terminal cTnI peptides are in progress. These results are expected to more completely characterize motional disorder observed at the interface, especially in cTnI.

In cTnC, hydrophobic residues whose chemical shifts are significantly perturbed upon complex formation include Leu97, Leu100, Met120, Leu121, Ile128, Phe156, Met157, 


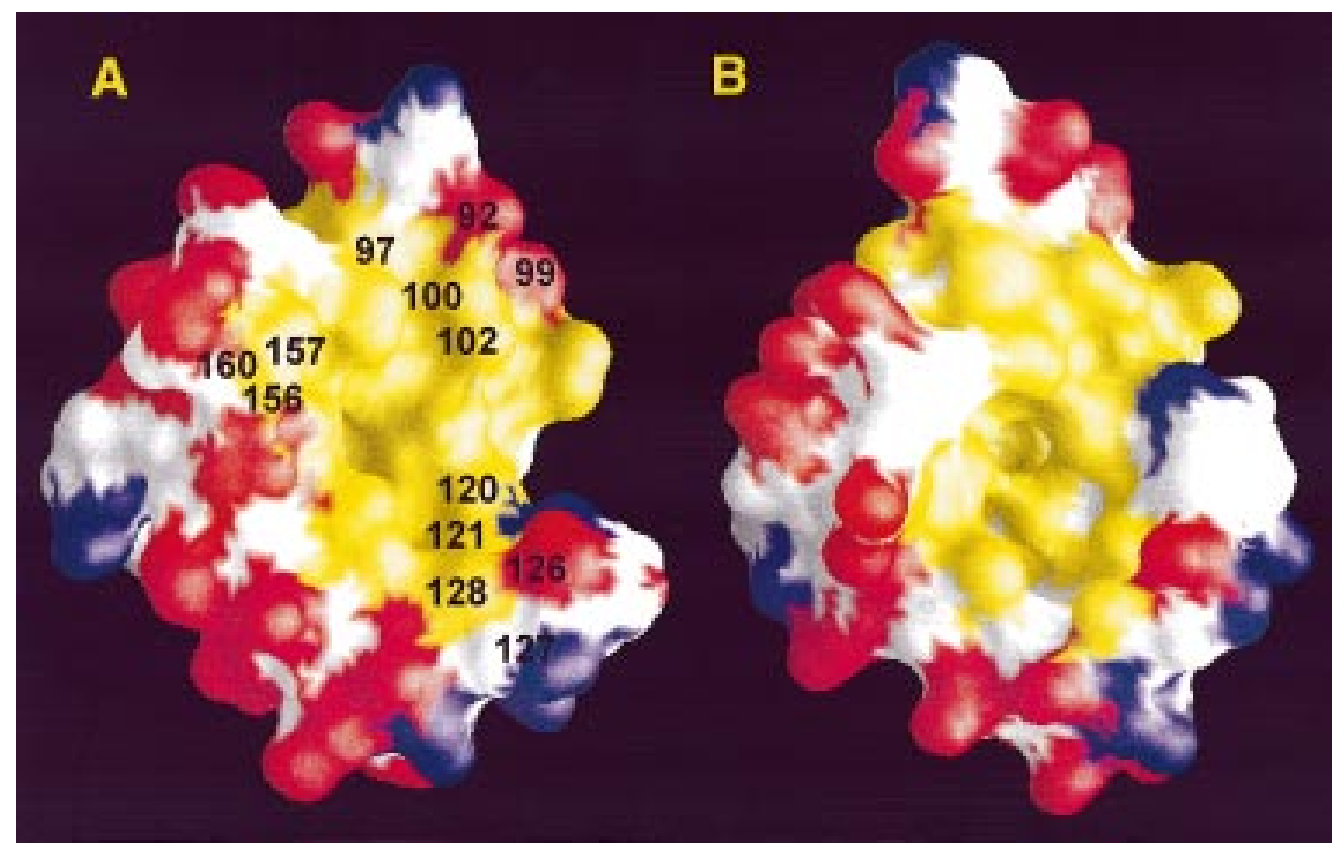

FIGURE 7: GRASP (54)-calculated molecular surfaces for $\mathrm{Ca}^{2+}$-saturated cTnC(81-161) bound to cTnI(33-80) and free in solution. (A) $\mathrm{Ca}^{2+}$-saturated $\mathrm{cTnC}(81-161)$ bound to $\mathrm{cTnI}(33-80)$. (B) $\mathrm{Ca}^{2+}$-saturated $\mathrm{cTnC}(81-161)$. Regions of hydrophobic, charged, and polar residues are colored yellow, red, and blue, respectively. Residues having the absolute value of the amide proton and/or amide nitrogen chemical shift difference between the free and cTnI(33-80)-bound forms greater than the average chemical shift difference plus one standard deviation are labeled. Average chemical shift differences plus one standard deviation in ${ }^{1} \mathrm{H}$ and ${ }^{15} \mathrm{~N}$ were 0.21 and 1.2 ppm, respectively.

and Val160. These residues correspond to hydrophobic residues Leu95, Cys98, Ile118, Phe119, Val126, Met154, Met155, and Va1158 in sTnC which make contact with sTnI$(1-47)$ in the crystal structure (6). In addition, polar interactions in the skeletal complex include Lys90, Glu97, Arg100, Arg104, Glu124, and His125 (6). These interactions correspond to cTnC residues Lys92, Asp99, Arg102, Lys106, Glu126, and Thr127 that also undergo significant amide proton and nitrogen chemical shifts upon complex formation in the cardiac complex. In the crystal structure of sTnC/sTnI(1-47), sTnI formed a 31 residue helix which was found to interact with both hydrophobic and amphiphilic amino acids in the C-terminal end of sTnC. However, the C-terminal end of $\operatorname{sinI}(1-47)$ was found to be disordered in the crystal structure. Interestingly, solution studies on $\left[{ }^{15} \mathrm{~N},{ }^{13} \mathrm{C}\right]$-labeled $\mathrm{cTnI}(33-80)$ bound to $\mathrm{cTnC}$ revealed a high degree of disorder at the protein-protein interface (Abbott, unpublished results). Disorder in the side chains of several resonances in the C-terminal domain of cTnC was also observed, along with conformational heterogeneity at the beginning of the $\mathrm{F}$ helix and at the end of the $\mathrm{H}$ helix in free $\mathrm{cTnC}(81-161)$.

Our results provide a direct comparison of solution structures for the $\mathrm{C}$-terminal domain of $\mathrm{cTnC}$ free and bound to the conserved $\mathrm{N}$-terminal domain of cTnI, corresponding to residues 33 through 80 . The tertiary structures of both the free and bound proteins are similar with the largest deviations occurring in the loop region between helices $\mathrm{F}$ and G. Comparison of interhelical angles shows that the bound form of $\mathrm{cTnC}(81-161)$ is more "open" than the free protein, providing a larger surface area for interaction with cTnI. Our data also show that unwinding of the linker region in $\mathrm{TnC}$ is not essential for $\mathrm{TnC} / \mathrm{TnI}$ complex formation. Unwinding of the linker region or central helix in sTnC was observed in the $2 \mathrm{Ca}^{2+} \mathrm{sTnC}$ complex with $\operatorname{sTnI}(1-47)(6)$. This permitted interaction of both the $\mathrm{N}$ - and $\mathrm{C}$-terminal domains of sTnC with sTnI(1-47). In the crystal structure, both regulatory sites in the $\mathrm{N}$-terminal domain are empty.
We have assigned the full-length $\mathrm{Ca}^{2+}$-saturated $\mathrm{cTnC}$ bound to $\operatorname{cTnI}(1-80, \mathrm{~S} 23 \mathrm{D}, \mathrm{S} 24 \mathrm{D})$, a stable mimetic for the phosphorylated form of cTnI, and see no significant backbone amide proton or nitrogen chemical shift changes in the $\mathrm{N}$-terminal domain of cTnC upon complex formation (Finley, unpublished). These studies, along with dynamic studies on $\mathrm{Ca}^{2+}$-saturated cTnC free and bound to $\mathrm{cTnI}(1-80, \mathrm{~S} 23 \mathrm{D}$, S24D), suggest that in the presence of saturating calcium the N-terminal domain of $\mathrm{cTnC}$ has little or no interaction with the phosphorylated form of the N-terminal domain of cTnI. Thus, important differences may exist in the nature of the molecular interactions between the $\mathrm{N}$-terminal domains of skeletal and cardiac $\mathrm{TnC}$ and the $\mathrm{N}$-terminal domain of TnI. However, the observation that $\mathrm{TnC}$ structures for both cardiac and skeletal C-terminal domains are similar indicates a common motif for the $\mathrm{Ca}^{2+} / \mathrm{Mg}^{2+}$-dependent $\mathrm{TnC}$ and $\mathrm{TnI}$ interaction site. The $\mathrm{C}$-terminal domain contains two highaffinity binding sites that under physiological conditions can be occupied by either $\mathrm{Ca}^{2+}$ or $\mathrm{Mg}^{2+}$. In both the cardiac and skeletal troponin systems, interaction between the C-terminus of $\mathrm{TnC}$ and the N-terminus of $\mathrm{TnI}$ is thought to be responsible for the tight association of the complex. In the cardiac complex, it is clear that the $\mathrm{N}$-terminus of TnI plays an additional role aside from maintaining tight association of the two proteins. The cardiac-specific amino terminus contains two protein kinase A sites that are known to modulate the $\mathrm{Ca}^{2+}$ sensitivity of the myofibrils upon phosphorylation. Phosphorylation at these sites has been demonstrated to modulate the calcium affinity at the regulatory site by altering the interactions between $\mathrm{cTnI}$ and $\mathrm{cTnC}$ (52). Cardiac TnI also contains two protein kinase C sites at Ser43 and Ser45 that are functionally significant, and it appears likely that phosphorylation of these sites may affect the cTnI-cTnC interface (53).

These studies provide the first direct comparison of the free and $\mathrm{cTnI}$ bound $\mathrm{C}$-terminal domain in $\mathrm{cTnC}$. Using the bound structure of $\mathrm{cTnC}(81-161)$, we have been able to map 
the binding site of the N-terminal domain of cTnI. Comparison of the bound cardiac structure with the crystal structure of the bound skeletal isoform shows that many of the binding interactions are conserved. The role and importance of particular amino acids can now be explored using site-directed mutagenesis. Structural studies on cTnC/cTnI(1-80) and $\mathrm{cTnC} / \mathrm{cTnI}(1-80, \mathrm{~S} 23 \mathrm{D}, \mathrm{S} 24 \mathrm{D})$, mimicking the PKA-phosphorylated N-terminus of cTnI, are now in progress. These studies will help elucidate the role of dynamics in transmission and modulation of the calcium signal.

\section{ACKNOWLEDGMENT}

We are grateful to Lewis Kay for providing the pulse sequences and Ranjith Muhandiram for technical assistance as well as to Drs. Feeney and Polshakov for providing us with their AngleSearch software and helpful discussions. We also thank Mark Rance for many useful discussions and Yuichiro Maeda for communicating portions of his work before publication.

\section{REFERENCES}

1. Van Eerd, J. P., \& Takahashi, K. (1976) Biochemistry 15, 1171-1180.

2. Spyracopoulos, L., Li, M. X., Sia, S. K., Gagne, S. M., Chandra, M., Solaro, R. J., \& Sykes, B. D. (1997) Biochemistry 36, 12138-12146.

3. Solaro, R. J., Ed. (1986) in Protein Phosphorylation in the Heart Muscle, pp 129-156, CRC Press Inc., Boca Raton, FL.

4. Krudy, G. A., Kleerekoper, Q., Guo, X., Howarth, J. W., Solaro, R. J., \& Rosevear, P. R. (1994) J. Biol. Chem. 269, 23731-23735.

5. Sia, S. K., Li, M. X., Spyracopoulos, L., Gagne, S. M., Liu, W., Putkey, J. A., \& Sykes, B. D. (1997) J. Biol. Chem. 272, 18216-18221.

6. Vassylyev, D. G., Takeda, S., Wakatsuki, S., Maeda, K., \& Maeda, Y. (1998) Proc. Natl. Acad. Sci. U.S.A. 95, 48474852.

7. Krudy, G. A., Brito, R. M. M., Putkey, J. A., \& Rosevear, P. R. (1992) Biochemistry 31, 1595-1602.

8. Jha, P. K., Leavis, P. C., \& Sarkar, S. (1996) Biochemistry $35,16573-16580$.

9. Wishart, D. S., Bigam, C. G., Yao, J., Abildgaard, F., Dyson, H. J., Oldfield, E., Markley, J. L., \& Sykes, B. D. (1995a) J. Biomol. NMR 6, 135-140.

10. Kay, L. E., Keifer, P., \& Saarinen, T. (1992) J. Am. Chem. Soc. 114, 10663-10665.

11. Zhang, O., Kay, L. E., Oliver, J. P., \& Forman-Kay, J. D. (1994) J. Biomol. NMR 4, 845-858.

12. Pascal, S. M., Muhandiram, Yamasaki, T., Forman-Kay, J. D., \& Kay, L. E. (1994) J. Magn. Reson., Ser. B 103, 197201.

13. Wittekind, M., \& Mueller, L. (1993) J. Magn. Reson. 101, 201-205.

14. Grzesiek, S., \& Bax, A. (1992) J. Am. Chem. Soc. 114, 62916293.

15. Kay, L. E., Xu, G. Y., \& Yamazaki, T. (1994) J. Magn. Reson., Ser. A 109, 129-133.

16. Logan, T. M., Olejnicazak, E. T., Xu, R. X., \& Fesik, S. W. (1993) J. Biomol. NMR 3, 225-231.

17. Grzesiek, S., Anglister, J., \& Bax, A. (1993) J. Magn. Reson., Ser. B 101, 114-119.

18. Montelione, G. T., Lyons, B. A., Emerson, S. D., \& Tashiro, M. (1992) J. Am. Chem. Soc. 114, 10974-10975.

19. Yamasaki, T., Forman-Kay, J. D., \& Kay, L. E. (1993) J. Am. Chem. Soc. 115, 11054-11055.

20. Vuister, G. W., \& Bax, A. (1993) J. Am. Chem. Soc. 115, 7772-7777.

21. Kuboniwa, H., Grzesiek, S., Delaglio, F., \& Bax, A. (1994) J. Biomol. NMR 4, 871-878.

22. Polshakov, V. I., Frenkiel, T. A., Birdsall, B., Soteriou, A., \& Feeney, J. (1995) J. Magn. Reson. 108, 31-43.
23. Archer, S. J., Ikura, M., Torchia, D. A., \& Bax, A. (1991) J. Magn. Reson. 95, 636-641.

24. Demarco, A., Llinas, M., \& Wüthrich, K. (1978) Biopolymers 17, 2727-2742.

25. Delaglio, F., Grzesik, S., Vuister, G. W., Zhu, G., Pfeifer, J., \& Bax, A. (1995) J. Biomol. NMR 6, 277-293.

26. Kirkpatrick, S., Gelatt, C. D., Jr., \& Vecchi, M. P. (1983) Science 220, 671-680.

27. Nilges, M., Clore, G. M., \& Gronenborn, A. M. (1988a) FEBS Lett. 229, 317-324.

28. Nilges, M., Clore, G. M., \& Gronenborn, A. M. (1988b) FEBS Lett. 239, 129-136.

29. Kuszewski, J., Nilges, M., \& Brünger, A. T. (1992) J. Biomol. NMR 2, 33-56.

30. Brünger, A. T. (1992) X-PLOR Manual, Yale University, New Haven, CT.

31. Strynadka, N. J., \& James, M. N. G. (1989) Annu. Rev. Biochem. 58, 951-998.

32. Bersch, B., Koehl, P., Nakatani, Y., Ourisson, G., \& Milon, A. (1993) J. Biomol. NMR 3, 443-461.

33. Wüthrich, K., Billeter, M., \& Braun, W. (1983) J. Mol. Biol. 169, 949-961.

34. Havel, T. F., \& Wüthrich, K. (1985) J. Mol. Biol. 182, 281294.

35. Laskowski, R. A., MacArthur, M. W., Moss, D. S., \& Thornton, J. M. (1993) J. Appl. Crystallogr. 26, 283-290.

36. MacArthur, M. W., \& Thornton, J. M. (1993) Proteins: Struct., Funct., Genet. 17, 232-251.

37. Farrow, N. A., Muhandiram, R., Singer, A. U., Pascal, S. M., Kay, C. M., Gish, G., Shoelson, S. E., Pawson, T., FormanKay, J. D., \& Kay, L. E. (1994) Biochemistry 33, 5984-6003.

38. Gagne, S. M., Tsuda, S., Li, M. X., Chandra, M., Smillie, L. B., \& Sykes, B. D. (1994) Protein Sci. 3, 1961-1974.

39. Spera, S., \& Bax, A. (1991) J. Am. Chem. Soc. 113, 54905492.

40. Wishart, D. S., \& Sykes, B. D. (1994) J. Biomol. NMR 4, $171-180$.

41. Wishart, D. S., Bigam, C. G., Holm, A., Hodges, R. S., \& Sykes, B. D. (1995b) J. Biomol. NMR 5, 67-81.

42. Brito, R. M. M., Putkey, J. A., Strynadka, N. C. J., James, M. N. G., \& Rosevear, P. R. (1991) Biochemistry 30, 1023610245.

43. Brito, R. M. M., Krudy, G. A., Negele, J. C., Putkey, J. A., \& Rosevear, P. R. (1993) J. Biol. Chem. 268, 20966-20973.

44. Dasgupta, S., \& Bell, J. A. (1993) Int. J. Pept. Protein Res. 41, 499-511.

45. Harper, E. T., \& Rose, G. D. (1993) Biochemistry 32, 76057609.

46. Gronenborn, A. M., \& Clore, G. M. (1994) J. Biomol. NMR 4, 455-458.

47. Herzberg, O., \& James, M. N. G. (1988) J. Mol. Biol. 203, $761-779$.

48. Gaponenko, V., Abusamhadneh, E., Abbott, M. B., Finley, N., Gasmi-Seabrook, G., Solaro, R. J., Rance, M., and Rosevear, P. R. (1999) J. Biol. Chem. 274, 16681-16686.

49. Cheng, J. W., Lepre, C. A., \& Moore, J. M. (1994) Biochemistry 33, 4093-4100.

50. Olejniczak, E. T., Zhou, M. M., \& Fesik, S. W. (1997) Biochemistry 36, 4118-4124.

51. Kay, L. E., Muhandiram, D. R., Wolf, G., Shoelson, S. E., \& Forman-Kay, J. D. (1998) Nat. Struct. Biol. 5, 156-163.

52. Chandra, M., Dong, W.-J., Pan, B. S., Cheung, H. C., \& Solaro, R. J. (1997) Biochemistry 36, 13305-13311.

53. Noland, T. A., Guo, X., Raynor, R. L., Averyhart-Fullard, V., Jideama, N. M., Averyhart-Fullard, V., Solaro, R. J., \& Kuo, J. F. (1995) J. Biol. Chem. 43, 25445-25454.

54. Nicholls, A., Sharp, K. A., \& Honig, B. (1991) Proteins: Struct., Funct., Genet. 11, 281-296.

BI9902642 